\title{
The Evaluation of the Effect of TENS Therapy on Reducing Acute and Chronic Pain Following Varicocelectomy
}

\author{
Dawood Agamohammadi', Haleh Farzin ${ }^{2}$, Solmaz Fakhari ${ }^{*}$, Roshide Siami ${ }^{2}$ \\ ${ }^{1}$ Fellowship of Pain and Palliative Care, Tabriz University of Medical Sciences, Tabriz, Iran \\ ${ }^{2}$ Tabriz University of Medical Science, Tabriz, Iran \\ Email: *solmaz_fakhari@yahoo.com
}

How to cite this paper: Agamohammadi, D., Farzin, H., Fakhari, S. and Siami, R. (2017) The Evaluation of the Effect of TENS Therapy on Reducing Acute and Chronic Pain Following Varicocelectomy. Open Journal of Internal Medicine, 7, 52-57.

https://doi.org/10.4236/ojim.2017.73005

Received: July 7, 2017

Accepted: August 6, 2017

Published: August 9, 2017

Copyright $\odot 2017$ by authors and Scientific Research Publishing Inc. This work is licensed under the Creative Commons Attribution International License (CC BY 4.0). http://creativecommons.org/licenses/by/4.0/

\section{Open Access}

\begin{abstract}
Introduction: Post-varicocelectomy pain is a considerable pain with probability of promotion toward chronicity. Some reasons, including surgical technique or nerve injury and inappropriate attention to treatment of acute pain play role in the emergence of acute pain. The pain could lead to limitation in movement and working, patient dissatisfaction and waste of medical resources. Transcutaneous electrical nerve stimulation (TENS) therapy as the patient control analgesia (PCA) is associated with reduction of pain intensity and analgesic consumptions. This study aimed to evaluate the effect of TENS therapy on reducing the acute and chronic pain following varicocelectomy. Methods and Materials: The study was conducted after obtaining the approval of the local Institute Ethics Committee and written informed consent from all of the patients. Eighty patients scheduled for undergoing varicocelectomy, were randomly classified according to a randomization list prepared using online software at a 1:1 ratio to Groups A (intervention group) and B (placebo group). In postoperative and recovery period, Group A received TENS therapy for 30 minutes in parallel to surgical scar with high frequency by sensory level. Group B was treated with off-device. The treatment course was replicated for the two groups at 2, 6, 12 and 24 hours after operation. Then, postoperative pain was measured by VAS (visual analogue scale) at the same time and after 1 week and 1, 2 and 3 months. The amount of used analgesics was recorded. Results: The results showed that based on the VAS, pain significantly decreased after intervention in 2 hours ( $25 \%$ with VAS $=5$ versus $32.5 \%$ with VAS $=8$ in control group). The differences among, amount of used analgesics at 2, 6 and 12 hours were significant with p-value $=0.001$, $<0.0001$ and $=0.02$, respectively. Conclusion: TENS therapy could efficiently decrease pain degree for hours, weeks and months after varicocelectomy; this
\end{abstract}


was associated with decreased post-operation analgesic requirements.

\section{Keywords}

Varicocelectomy, TENS, Pain

\section{Introduction}

From October 2010 to 2011 was named as global year against acute pain. Acute postoperative pain by interaction with several physiologic functions of organ systems can impair their function and result in mortality; however, it is important to consider treating acute pain [1]. Pain related to varicocelectomy can become chronic due to surgery technique damaging neuronal fibers. It has some reasons such as outpatient surgery and inadequate pain treatment. It can entail limited movement, problems in working, patient dissatisfaction and unnecessary consumption of treatment resources and long stay in the hospital. Overall, history and prevalence of pain are unknown [2]. The prevalence of varicocele in normal population is $15 \%$ to $20 \%$ and in infertile men is $68 \%$ to $81 \%$ with $2 \%$ to $10 \%$ prevalence of pain. Its actual etiology is yet unknown [3] [4]. Subinguinal microscopic surgery technique has led to less pain and side effects compared to other techniques [4] [5]. Transcutaneous electrical stimulation (TENS) is a nonpharmacologic and non-invasive, safe, inexpensive and easily applicable approach to reduce pain that stimulates transcutaneous peripheral nerves and creates a painless situation [6] [7]. The measurement of pain is usually based on the Visual Analogue Scale (VAS) and the Numerical Verbal Rating Scale(NVRS), but recently, cortisol level can be a good indicator of pain measurement during postoperative TENS therapy [8]. Several studies demonstrated that in spinal anesthesia and incision site infiltration with local anesthetics, TENS was more efficient than general anesthesia, causing complete nociceptive block and preventing spinal stimulations [9]. Therefore, we decided to conduct two-blinded clinical trial to evaluate control rate of acute pain, chronicity rate of pain, chronic pain intensity and analgesic consumption rate during postoperative period after varicocelectomy.

\section{Methods and Materials}

In this clinical trial, we randomly selected 80 patients undergoing varicocelectomy from July 2012 to March 2013 by easy non-probable sampling and classified two groups. Inclusion criteria included all patients undergoing varicocelectomy by high-ligation technique, ASAI-II, and aged between 20 and 40 years old. Patients with previous history of analgesic consumption, addiction, depression, psychosis and overweight were excluded from the study. After obtaining informed consent, the patients were divided into Group A (intervention group) and Group B (placebo group). Premedication with $1 \mu \mathrm{g} / \mathrm{kg}$ fentanyl and 0.01 
$\mathrm{mg} / \mathrm{kg}$ midazolam, induction with $2 \mathrm{mg} / \mathrm{kg}$ propofol and $0.4 \mathrm{mg} / \mathrm{kg}$ atracurium were administered. For security of airway, laryngeal mask airway was inserted. Anesthesia was maintained with inhaler anesthetics (i.e. $\mathrm{N}_{2} \mathrm{O} 50 \%+\mathrm{O}_{2} 50 \%+$ isoflurane $1 \%-1.5 \%)$. At the end of high ligation varicocelectomy, the patient was extubated and transported to post anesthesia care unit. In the recovery room, TENS pads were inserted at $4 \mathrm{~cm}$ distance and parallel with incision site. After complete recovery, both groups received TENS with high frequency (100 HZ). Group A received current intensity at sensory level for 30 minutes, whereas Group B received current intensity equal to zero (placebo). These steps were performed by different persons. The evaluation of pain method was preoperatively explained to the patient (i.e. determinate by a special ruler, zero $=$ complete analgesia, $10=$ most severe pain). TENS therapy was repeated at 2, 6, 12 and 24 hours. The pain severity at recovery 2, 6, 12 and 24 hours after TENS therapy and the amount of analgesic consumption (meperidine) or its equal (NSAIDs) were recorded. After discharge, pain severity (NVRS) and NSAIDs consumption (mg/ $1^{\text {st }}$ week, $1^{\text {st }}$ month, $2^{\text {th }}$ and $3^{\text {th }}$ month) were recorded. Parametric tests (independent T-test) and non-parametric tests (Mann-Whitney, chi-square and Fisher exact test) were used for statistical analysis. P-value $<0.05$ was considered significant.

\section{Results}

Demographic information is shown in the Table 1. In weight, age, preoperative smoking, there were no significant relationship between the two groups. The results showed that in placebo group, 13 patients $(32.5 \%)$ had pain score equal with 8 at 2 hours after operation and pain score of 10 patients (25\%) was 6. At 6 hours after surgery, pain score 5 in 15 cases (37.5\%) and pain score 6 and 7 in 9 patients $(22.5 \%)$ were showed.

At 12 hours after surgery, pain scores 4 and 5 were calculated in $27.5 \%$ and $30 \%$ of cases. After 24 hours, pain scores 3 and 5 were observed in 12 patients $(30 \%)$, respectively. One week after surgery, pain score 2 (15 cases, $37.5 \%)$ and pain score 4 in $30 \%$ of cases were calculated.

After one month, pain score 1 was reported in $40 \%$ of cases. In this group, opioid consumption amount in the first 2 hours was $42.5 \%$ (Table 2).

In the intervention group, 10 patients who received TENS therapy, had pain score 5 at 6 hours, VAS score was 3 to 6 post-operative. At 12 hours, pain scores 2 and 3 were seen in $37.5 \%$ and in 24 hours, pain scores 1 and 2 was $25 \%$. After

Table 1. Demographic and basic data in two groups.

\begin{tabular}{ccccc}
\hline & & TENS group & Placebo group & P-value \\
\hline \multirow{2}{*}{ Weight $(\mathrm{kg})$} & & $12.90 \pm 8.15$ & $13.02 \pm 8.25$ & 0.948 \\
Age (month) & & $25.60 \pm 5.48$ & $27.13 \pm 5.27$ & 0.207 \\
\cline { 3 - 4 } Smooking & Yes & $31(77.5 \%)$ & $27(67.5 \%)$ & 0.405 \\
& No & $9(22.5 \%)$ & $13(32.5 \%)$ & \\
\hline
\end{tabular}


Table 2. Data base on the frequency of pain score (VAS) in placebo and TENS group. Score; score of pain.

\begin{tabular}{|c|c|c|c|c|c|c|c|c|c|c|c|c|c|c|}
\hline Time & VAS & 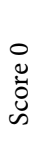 & 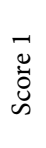 & 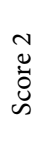 & $\begin{array}{l}m \\
\stackrel{0}{0} \\
\ddot{U}\end{array}$ & $\begin{array}{l}\text { H } \\
\stackrel{0}{0} \\
\ddot{~}\end{array}$ & $\begin{array}{l}n \\
0 \\
\ddot{0} \\
\ddot{D}\end{array}$ & $\begin{array}{l}0 \\
\stackrel{0}{0} \\
\ddot{U}\end{array}$ & $\begin{array}{l}\hat{0} \\
\stackrel{0}{0} \\
\ddot{u}\end{array}$ & $\begin{array}{l}\infty \\
\stackrel{0}{0} \\
\ddot{U} \\
\leftrightarrow\end{array}$ & 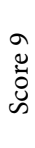 & $\begin{array}{l}\circ \\
\stackrel{0}{0} \\
\stackrel{0}{0} \\
\infty\end{array}$ & $\begin{array}{l}0 \\
\text { क } \\
+1 \\
\text { हే } \\
\sum\end{array}$ & 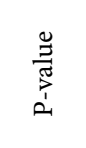 \\
\hline \multirow{3}{*}{2 hours after surgery } & TENS group & 0 & 0 & 1 & 2 & 6 & 10 & 5 & 8 & 7 & 1 & 0 & $1.69 \pm 0.9$ & \multirow{3}{*}{$<0.001$} \\
\hline & & & & & & & & & & & & & & \\
\hline & Placebo group & 0 & 0 & 0 & 0 & 3 & 2 & 10 & 8 & 13 & 4 & 0 & $6.95 \pm 1.37$ & \\
\hline \multirow[t]{2}{*}{6 hours after surgery } & TENS group & 0 & 1 & 2 & 8 & 10 & 8 & 8 & 3 & 0 & 0 & 0 & $1.46 \pm 0.7$ & \multirow[t]{2}{*}{$<0.001$} \\
\hline & Placebo group & 0 & 0 & 1 & 0 & 2 & 15 & 9 & 9 & 4 & 0 & 0 & $5.85 \pm 1.27$ & \\
\hline \multirow{3}{*}{12 hours after surgery } & TENS group & 1 & 4 & 13 & 10 & 8 & 4 & 0 & 0 & 0 & 0 & 0 & $1.24 \pm 0.5$ & \multirow{3}{*}{$<0.001$} \\
\hline & & & & & & & & & & & & & & \\
\hline & Placebo group & 0 & 1 & 0 & 6 & 11 & 12 & 7 & 3 & 0 & 0 & 0 & $4.65 \pm 1.29$ & \\
\hline \multirow{2}{*}{24 hours after surgery } & TENS group & 10 & 15 & 10 & 4 & 0 & 1 & 0 & 0 & 0 & 0 & 0 & $1.11 \pm 0.5$ & \multirow{2}{*}{$<0.001$} \\
\hline & Placebo group & 1 & 0 & 7 & 12 & 8 & 12 & 0 & 0 & 0 & 0 & 0 & $3.55 \pm 1.23$ & \\
\hline \multirow{2}{*}{ One week after surgery } & TENS group & 33 & 6 & 1 & 0 & 0 & 0 & 0 & 0 & 0 & 0 & 0 & $4.6 \pm 0.2$ & \multirow{2}{*}{$<0.001$} \\
\hline & Placebo group & 1 & 7 & 15 & 5 & 12 & 0 & 0 & 0 & 0 & 0 & 0 & $2.50 \pm 1.17$ & \\
\hline \multirow[b]{2}{*}{ One month after surgery } & TENS group & 40 & 0 & 0 & 0 & 0 & 0 & 0 & 0 & 0 & 0 & 0 & 0 & \multirow[b]{2}{*}{$<0.001$} \\
\hline & Placebo group & 11 & 16 & 7 & 6 & 0 & 0 & 0 & 0 & 0 & 0 & 0 & $1.2 \pm 1.01$ & \\
\hline \multirow{2}{*}{2 months after surgery } & TENS group & 40 & 0 & 0 & 0 & 0 & 0 & 0 & 0 & 0 & 0 & 0 & 0 & \multirow{2}{*}{0.005} \\
\hline & Placebo group & 32 & 5 & 3 & 0 & 0 & 0 & 0 & 0 & 0 & 0 & 0 & $0.27 \pm 0.59$ & \\
\hline 3 months after surgery & TENS group & 40 & 0 & 0 & 0 & 0 & 0 & 0 & 0 & 0 & 0 & 0 & 0 & $<0.001$ \\
\hline
\end{tabular}

Table 3. Data about consumption of opioid (meperidine) in placebo and TENS group.

\begin{tabular}{|c|c|c|c|c|c|c|c|c|}
\hline \multirow{2}{*}{\multicolumn{2}{|c|}{$\begin{array}{l}\text { Opioid amount } \\
\text { hour }\end{array}$}} & \multicolumn{5}{|c|}{ Opioid (mg) in percentage of patients } & \multirow{2}{*}{ Mean \pm SD } & \multirow{2}{*}{ P-value } \\
\hline & & $0 \mathrm{mg}$ & $12.5 \mathrm{mg}$ & $20 \mathrm{mg}$ & $25 \mathrm{mg}$ & $30 \mathrm{mg}$ & & \\
\hline \multirow{2}{*}{2 hours after surgery } & TENS group & $62.5 \%$ & $10 \%$ & 0 & $27.5 \%$ & 0 & $11.16 \pm 8.12$ & \multirow{2}{*}{0.514} \\
\hline & Placebo group & $17.5 \%$ & $7.5 \%$ & $32.5 \%$ & $42.5 \%$ & 0 & $9.11 \pm 18.06$ & \\
\hline \multirow{2}{*}{6 hours after surgery } & TENS group & $95 \%$ & 0 & 0 & $2.5 \%$ & $2.5 \%$ & $6.9 \pm 1.37$ & \multirow[b]{2}{*}{0.861} \\
\hline & Placebo group & $60 \%$ & $7.5 \%$ & $15 \%$ & $17.5 \%$ & 0 & $10.71 \pm 8.31$ & \\
\hline \multirow{2}{*}{12 hours after surgery } & TENS group & $100 \%$ & 0 & 0 & 0 & 0 & 0 & \multirow{2}{*}{$<0.001$} \\
\hline & Placebo group & $87.5 \%$ & $7.5 \%$ & $8 \%$ & 0 & 0 & $5.35 \pm 1.93$ & \\
\hline
\end{tabular}

one week, pain score in $82.5 \%$ was zero and only $15 \%$ had pain score 6 (Table 2).

In comparison with the placebo group, pain score was lower after surgery. The variables correlations regard to pain score after 2 hours after surgery based on VAS had P-Value $=0.003$. In other intervals-Value $<0.0001$ was considered significant. The comparison of pain score in the second month showed $\mathrm{P}-\mathrm{Value}=$ 0.003 and the difference among, amount of used analgesics at 2, 6 and 12 hours were significant with $\mathrm{p}$-value $=0.001,<0.0001$ and $=0.02$, respectively (Table 3 ). 
In all of these variables and comparisons, p-value was significant. Thus, these results demonstrated that TENS therapy in controlling acute and chronic pain after surgery had statistically significant correlation. Low opioid consumption was observed in the intervention group.

\section{Discussion}

Varicocele is one cause of male infertility with negative effects on the sperm parameters. Varicocelectomy is one of the effective approaches for the treatment of varicocele and is associated with significant implication on sperm parameters, but after surgery, pain is the most important concern due to somatic and emotional effects on human life [1] [2]. There are several pharmacologic and non-pharmacologic methods to control of postoperative pain. Ahmed et al. Concluded that using TENS acts as an index of important and efficient postoperative pain after inguinal hernia operation without side effects and continuation of pain reduction until one month [2]. Matthew et al. demonstrated that TENS may reduce postoperative phantom pain on movement and at rest [10]. Our results indicated TENS effects for 3 month after surgery [6]. Wang et al. showed that TENS with high frequency $(100 \mathrm{~Hz})$ effects was superior to low frequency $(2 \mathrm{~Hz})$. In this study, we used only high frequency. In this regard, some maintained that spinal anesthesia and infiltration of incision cite, as well as TENS application were more efficient than general anesthesia, probably due to complete block of nociceptive and prevention of spinal movement [9]. In one study, Lewis defined using TENS as an alternative approach for pain reduction in osteoarthritis [11]. After 3 weeks, a significant difference between case and control groups was observed, like as our study. The results obtained by Chen et al. were the same as of those of the present study, i.e. remarkable TENS therapy effect on acute pain reduction rate and postoperative analgesic consumption [12]. In a study De Sanata et al. demonstrated that TENS therapy could result in reducing pain score and total postoperative analgesic consumption [13]. This result was in parallel with our study. Our results showed that unpleasant sense due to pain in case group was lower than the control group. Using TENS with modulation of frequency and effect on nociceptive and neuropathic pain can decrease pain and increase endothelial growth factor from the vascular wall [14] [15]. It seems that TENS by its artificial stimulation can stimulate large myelinated nerves (e.g. A $\beta$ fibers) to disconnect the non-myelinated $\mathrm{C}$ nerves in spinal pathway that contain pathologic impulses in dorsal horn of spinal cord [6] [15].

\section{Conclusion}

In the present study, TENS plays a safe and non-invasive role in reducing acute and chronic pain as well as analgesics consumption.

\section{References}

[1] Miller, R.D., et al. (2009) Anesthesia. Elsevier Health Sciences, Amsterdam. 
[2] Altunoluk, B., et al. (2010) Duration of Preoperative Scrotal Pain May Predict the Success of Microsurgical Varicocelectomy. International Brazilian Journal of Urology, 36, 55-59. https://doi.org/10.1590/S1677-55382010000100009

[3] Yaman, Ö., et al. (2000) Effect of Microsurgical Subinguinal Varicocele Ligation to Treat Pain. Urology, 55, 107-108. https://doi.org/10.1016/S0090-4295(99)00374-X

[4] Chen, S.S. and Huang, W.J. (2010) Experience of Varicocele Management during Ipsilateral Inguinal Herniorrhaphy: A Prospective Study. Journal of the Chinese Medical Association, 73, 248-251. https://doi.org/10.1016/S1726-4901(10)70053-8

[5] Jarrow, J. (2001) Effects of Varicocele on Male Infertility. Human Reproduction Update, 7, e64.

[6] Ahmed, M.T. (2010) Effect of Transcutaneous Electrical Nerve Stimulation on Postoperative Pain after Inguinal Hernia Repair: A Randomized Placebo-Controlled Trial. Turkish Journal of Physical Medicine, 56, 170-176.

[7] Amid, P.K., Shulman, A.G. and Lichtenstein, I.L. (1994) Local Anesthesia for Inguinal Hernia Repair Step-by-Step Procedure. Annals of Surgery, 220, 735.

https://doi.org/10.1097/00000658-199412000-00004

[8] Wang, B., et al. (1997) Effect of the Intensity of Transcutaneous Acupoint Electrical Stimulation on the Postoperative Analgesic Requirement. Anesthesia \& Analgesia, 85, 406-413. https://doi.org/10.1213/00000539-199708000-00029

[9] Chiu, J.H., et al. (1999) Effect of Transcutaneous Electrical Nerve Stimulation for Pain Relief on Patients Undergoing Hemorrhoidectomy. Diseases of the Colon \& Rectum, 42, 180-185. https://doi.org/10.1007/BF02237124

[10] Mulvey, M.R., et al. (2013) Transcutaneous Electrical Nerve Stimulation for Phantom Pain and Stump Pain in Adult Amputees. Pain Practice, 13, 289-296. https://doi.org/10.1111/j.1533-2500.2012.00593.x

[11] Lewis, D., Lewis, B. and Sturrock, R.D. (1984) Transcutaneous Electrical Nerve Stimulation in Osteoarthrosis: A Therapeutic Alternative? Annals of the Rheumatic Diseases, 43, 47-49. https://doi.org/10.1136/ard.43.1.47

[12] Chen, L., et al. (1998) The Effect of Location of Transcutaneous Electrical Nerve Stimulation on Postoperative Opioid Analgesic Requirement: Acupoint versus Nonacupoint Stimulation. Anesthesia \& Analgesia, 87, 1129-1134. https://doi.org/10.1213/00000539-199811000-00028

[13] DeSantana, J.M., et al. (2008) Hypoalgesic Effect of the Transcutaneous Electrical Nerve Stimulation Following Inguinal Herniorrhaphy: A Randomized, Controlled Trial. The Journal of Pain, 9, 623-629. https://doi.org/10.1016/j.jpain.2008.01.337

[14] Bevilacqua, M., et al. (2007) Induction of Vascular Endothelial Growth Factor Release by Transcutaneous Frequency Modulated Neural Stimulation in Diabetic Polyneuropathy. Journal of Endocrinological Investigation, 30, 944. https://doi.org/10.1007/BF03349242

[15] Hamza, M.A., et al. (2000) Percutaneous Electrical Nerve Stimulation: A Novel Analgesic Therapy for Diabetic Neuropathic Pain. Diabetes Care, 23, 365-370. https://doi.org/10.2337/diacare.23.3.365 
Submit or recommend next manuscript to SCIRP and we will provide best service for you:

Accepting pre-submission inquiries through Email, Facebook, LinkedIn, Twitter, etc. A wide selection of journals (inclusive of 9 subjects, more than 200 journals)

Providing 24-hour high-quality service

User-friendly online submission system

Fair and swift peer-review system

Efficient typesetting and proofreading procedure

Display of the result of downloads and visits, as well as the number of cited articles Maximum dissemination of your research work

Submit your manuscript at: http://papersubmission.scirp.org/

Or contact ojim@scirp.org 